\title{
Complex segregation analysis of facial melasma in Brazil: evidence for a genetic susceptibility with a dominant pattern of segregation
}

\author{
Nicole França Holmo ${ }^{1}$ Geovana Brotto Ramos ${ }^{2} \cdot$ Heloisa Salomão ${ }^{2} \cdot$ Renata lani Werneck $^{3}$ (D) \\ Marcelo Távora Mira ${ }^{2}\left[\right.$ ] Luciane Donida Bartoli Miot ${ }^{1} \cdot$ Hélio Amante Miot ${ }^{1}{ }^{\circledR}$
}

Received: 11 April 2018 / Revised: 22 August 2018 / Accepted: 27 August 2018 / Published online: 30 August 2018

(c) Springer-Verlag GmbH Germany, part of Springer Nature 2018

\begin{abstract}
Despite high prevalence, the etiopathology of melasma is not fully understood. Nevertheless, many factors have been associated with the disease, including: sun exposure, sex steroids hormones, drugs, stress, and pregnancy. The high occurrence within familiars (40-60\%) suggests a genetic predisposition to the disease. This study explored, through complex segregation analysis (CSA), the inheritance model that best fit the family segregation pattern of facial melasma when accounting for the main epidemiological risk factors. We evaluated 686 subjects from 67 families, and 260 (38\%) of them had facial melasma. The CSA model, adjusted for age, skin phototype, sex, sun exposure at work, hormonal oral contraceptive, and pregnancy, evidenced a genetic component that was best fitted to a dominant pattern of segregation. Melasma results from an interaction between exposure factors (e.g. pregnancy, hormones, and sun exposure) over genetically predisposed individuals.
\end{abstract}

Keywords Melasma $\cdot$ Heredity $\cdot$ Genetics $\cdot$ Inheritance patterns $\cdot$ Pigmentary disorders

Hélio Amante Miot

heliomiot@gmail.com

Nicole França Holmo

nicole_franca@hotmail.com

Geovana Brotto Ramos

geovanabramos@hotmail.com

Heloisa Salomão

helo_salomao@hotmail.com

Renata Iani Werneck

renata.iani@pucpr.br

Marcelo Távora Mira

m.mira@pucpr.br

Luciane Donida Bartoli Miot

lucianemiot@fmb.unesp.br

1 Departamento de Dermatologia e Radioterapia, SN, FMB-

Unesp, Campus de Rubião Jr., Botucatu, SP CEP 18618-000, Brazil

2 Programa de Pós-Graduação em Ciências da Saúde, Escola de Medicina, Pontifícia Universidade Católica do Paraná, Curitiba, PR, Brazil

3 Programa de Pós-Graduação em Odontologia, Escola de Ciências da Vida, Pontifícia Universidade Católica do Paraná, Curitiba, PR, Brazil

\author{
Abbreviations \\ UNESP Universidade Estadual Paulista Júlio de Mes- \\ quita Filho \\ HOC Hormonal oral contraception \\ CSA Complex segregation analysis \\ OR Odds ratio \\ IC 95\% 95\% confidence interval
}

\section{Introduction}

Melasma is a common acquired chronic focal hypermelanosis that affects photoexposed areas (especially the face), mainly in women during fertile age, and its incidence seems to have increased in the last decade [1-3]. The occurrence in visible areas and its common recurrence despite treatment lead to a substantial impact on quality of life [4-6].

The etiopathology of melasma is not fully understood; however, many factors have been reported as triggering or aggravating the disease, such as: sun exposure, hormonal oral contraception (HOC), hormone replacement therapy, cosmetics, photosensitising drugs, pregnancy, and stress [7]. The high occurrence within familiars (40-60\%) and the association with African ancestry miscegenation suggest a genetic predisposition to the disease $[3,8]$. 
Complex segregation analysis (CSA) is a primary study within genetic epidemiology to explore the evidence that a genetic component (called 'major gene') underlies the distribution of a phenotype in a population. It has been used to advance the understanding of the genetic basis of complex (multifactorial) diseases. The CSA is composed of several statistical models that include the epidemiologic risk factors and the different parameters expected for inheritance models with the aim to compare which of them promotes best fit to the sample data. The CSA is indicated to explore multifactorial disorders in which the exposure factors interact with the genetic susceptibility in the development of a phenotype [9]. In this study, we performed a CSA in families with facial melasma.

\section{Methods}

A cross-sectional study of CSA was performed [9] that included patients with melasma from the dermatology clinic at FMB-Unesp (Botucatu, SP, Brazil) who reported some other familiar with the disease. The project was approved by the institutional review board. Patients were personally interviewed. Families in which some component could not be assessed were not included in the study. The variables evaluated were: current melasma, age, sex, use of HOC, pregnancy, working exposure to the sun, and hair/skin color phenotype (I-IV): I—fair skin and light hair; II—fair skin, dark hair; III—-light brown skin, dark hair; and IV—dark brown/black skin, curled dark hair.

First, a multivariate logistic regression was performed to assess the association between classic epidemiologic factors and melasma. The effect size was estimated by odds ratio (OR) and its 95\% confidence interval (IC 95\%) [10, 11].

All variables that resulted statistically significative $(p<0.05)$ in the logistic analysis were included in the CSA models, which tested the fit of the data to different models of segregation (stepwise procedure). The performances of the segregation models were compared by the $(-2 \operatorname{lnL})$ likelihood ratio. The best fit model to the data should result in the lower likelihood ratio value [12].

In $\mathrm{CSA}$, subjects of ousiotypes $\mathrm{AA}, \mathrm{AB}$, and $\mathrm{BB}$ are expected to segregate component ' $A$ ' to their offspring with the transmission probabilities: $\mathrm{sAA}, \mathrm{sAB}$, and $\mathrm{sBB}$. In a major gene model, segregation is assumed to be through a single autosomal locus with two alleles. Allele frequencies are denoted qA and 1-qA. Residual familial correlations were also considered according to mother/offspring ratio.

First, we carried out a sporadic transmission model (model I) that included only the non-genetic covariates. Next, in addition to the non-genetic covariates, the dependence on phenotypes of preceding relatives (mother-offspring transmission), which is parameterised in terms of familial correlations (model II), was assessed. To rule out the possibility of significant familial dependency due to unmeasured shared environmental factors (e.g. unprotected sun exposure leisure time or geographic location), our next step was to include a major gene effect in the model (models III and IV), with and without familial dependency. Finally, an additional model that includes a major gene effect was considered (model V) as a general transmission (non-Mendelian) to benchmark the structure of CSA as a satisfactory model for explaining the data and validating the ' $\tau$ ' transmission parameter [9].

Data were analysed with package SEGREG from S.A.G.E. 6.1.0 (2010): Statistical Analysis for Genetic Epidemiology, http://darwin.cwru.edu/sage/.

\section{Results}

We evaluated 686 subjects from 67 families, 260 (38\%) of whom had facial melasma. There was a mean of 10.2 subjects and 3.9 cases per family. The mean prevalence of melasma was $37.8 \%$ of the sample: $56.4 \%$ in women and $16.3 \%$ in men. The main epidemiological data are summarised in Table 1. Constitutional elements, such as darker phototypes and female sex; environmental exposure factors, such as sun exposure at work; and hormonal factors, such as HOC and pregnancy; were remarkable.

Table 2 discloses the main results of the CSA. The best fit model (lowest value of $-2 \ln L$ ) predicts the presence of a genetic component (major gene), with a dominant pattern of segregation in addition to the epidemiological risk factors, in explaining the disease occurrence.

\section{Discussion}

Skin melanin pigmentation in humans presents a polygenic inheritance and involves a complex cellular interaction of a large contingent of genes and regulatory factors that are not completely understood [13-17]. There is evidence that melanin pigmentation in melasma differs from other acquired pigmentary disorders such as tanning, post-inflammatory hyperpigmentation, lentigines, ephelides, and mastocytosis. There is also involvement of the whole epidermal melanin unit in the process (not just hypertrophic melanocytes), including mastocytes, fibroblasts, and endothelium-derived cytokines, and there are upper dermal abnormalities $[16,18$, 19]. Since melasma has no animal models for experimental research, most of the studies on pathophysiology and treatment of melasma are dependent on clinical investigations.

Our results indicated a genetic susceptibility to the development of facial melasma with a dominant pattern of segregation. The major gene dominant with residual 
Table 1 Main clinical and epidemiologic data from the sample

\begin{tabular}{llllr}
\hline & Melasma $(n=260)$ & Control $(n=426)$ & OR $(\text { IC 95\% })^{\mathrm{a}}$ & $p$ value $^{\mathrm{a}}$ \\
\hline Female sex & be & $160(38)$ & $12.5(8.0-19.5)$ & $<\mathbf{0 . 0 1}$ \\
Age & $44.5(13.9)$ & $44.6(20.8)$ & & \\
Corrected age & - & - & $1.1(1.1-1.2)$ & $<\mathbf{0 . 0 1}$ \\
Pregnancy $^{\mathrm{b}}$ & $173(67)$ & $103(24)$ & & \\
HOC $^{\mathrm{b}}$ & $182(70)$ & $87(20)$ & $14.3(4.0-50.0)$ & $<\mathbf{0 . 0 1}$ \\
Pregnancy $\times$ HOC & - & - & $1.6(1.1-2.3)$ & $\mathbf{0 . 0 3}$ \\
Working outdoor $^{\mathrm{b}}$ & $117(45)$ & $181(43)$ & & $\mathbf{0 . 0 4}$ \\
Skin phototype $^{\mathrm{b}}$ & & & $1.0(-)$ & \\
I & $20(8)$ & $49(12)$ & $1.6(0.8-3.1)$ & \\
II & $111(43)$ & $196(46)$ & $2.1(1.1-4.1)$ & \\
III & $109(42)$ & $144(34)$ & $1.6(0.7-4.0)$ & \\
IV & $20(8)$ & $37(9)$ & & \\
\hline
\end{tabular}

Bold values: $\mathrm{p}<0.05$

Hosmer-Lemeshow test $=0.49$; correct classification: $77 \%$; $p$ (model $)<0.01$

HOC hormonal oral contraception, Corrected age a parabolic function to linearize the incidence peak of melasma at 30 years-old and the interception at 16 and 65 years-old (data estimated from the sample), Pregnancy $\times$ HOC interaction between the factors

${ }^{\mathrm{a}}$ Multivariate adjust; ${ }^{\mathrm{b}} n(\%) ;{ }^{\mathrm{c}}$ Mean (SD) familial correlation (model III) and the major gene dominant (model IV) resulted in the best fit models (lower -2Ln values) compared to sporadic segregation (model I) and familial correlation alone (model II). Since model IV is composed of fewer parameters (without familiar correlation), and the fit index is very close to model III, it resulted the most parsimonious explanation for the phenomenon. Other possible patterns of segregation (e.g. recessive and codominant) were automatically excluded from the analysis by the CSA software stepwise procedure.

These results present limitations inherent in CSA studies. A single-centre research limits the generalisation of results, although increasing the homogeneity of the group reduces possible interference of transcultural variables. Moreover, melasma patients in this study presented epidemiologic characteristics similar to other Brazilian studies $[3,20]$.
Our results must also be confirmed in patients with extrafacial melasma, men, and other populations with different genetic ancestral components (e.g. Middle Eastern and Far Eastern). The estimated prevalence of the trait within affected families inflated the frequency of the disease (our group: $38 \%$, versus the same population estimate: $22 \%$ ); nevertheless, that is the only way to study segregation through generations.

CSA is a preliminary study in genetic epidemiology, and identifying a pattern of segregation does not allow for inference of which genes are involved in the process, requiring further investigation, such as linkage analysis or genome-wide type exploration.

\section{Conclusion}

The pattern of segregation of the susceptibility in facial melasma was best fitted to a dominant inheritance model, and exposure factors (e.g. pregnancy or sun exposure) can lead to disease development in genetically predisposed individuals. 


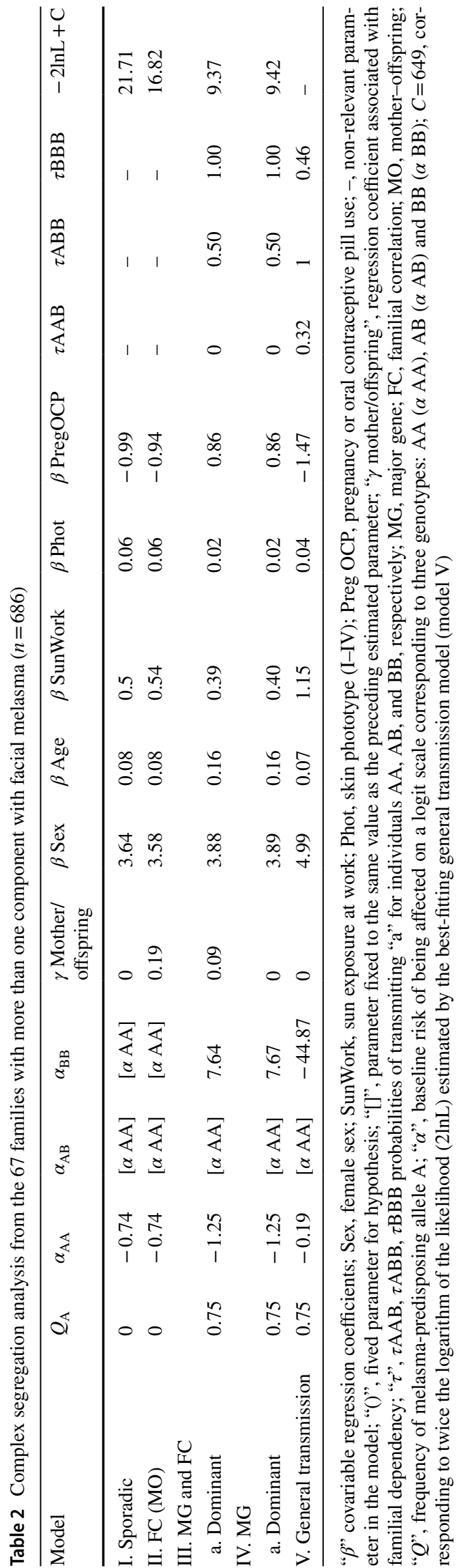

Author contributions Study design: HAM, NFH, LDB, MM. Data collection and tabulation: HAM, NFH, LDB. Data analysis: HAM, MM, RIW. CSA analysis: GBR, HS, MM, RIW. Paper writing: HAM, NFH, LDB, MM. Final revision and text approval: all authors.

Funding There is no funding source.

\section{Compliance with ethical standards}

Conflict of interest The authors declare that they have no conflict of interest.

Ethical approval This project was approved by the Unesp medical School Review Board (No. 476.936).

\section{References}

1. Ishiy PS, Silva LR, Penha MA, Handel AC, Miot HA (2014) Skin diseases reported by workers from UNESP campus at Rubiao Jr, Botucatu-SP (Brazil). An Bras Dermatol 89:529-531

2. Miguel LMZ, Jorge MFS, Rocha B, Miot HA (2017) Incidence of skin diseases diagnosed in a public institution: comparison between 2003 and 2014. An Bras Dermatol 92:423-425

3. Tamega Ade A, Miot LD, Bonfietti C et al (2013) Clinical patterns and epidemiological characteristics of facial melasma in Brazilian women. J Eur Acad Dermatol Venereol 27:151-156

4. Freitag FM, Cestari TF, Leopoldo LR, Paludo P, Boza JC (2008) Effect of melasma on quality of life in a sample of women living in southern Brazil. J Eur Acad Dermatol Venereol 22:655-662

5. Pollo CF, Miot LDB, Meneguin S, Miot HA (2018) Factors associated with quality of life in facial melasma: a cross-sectional study. Int J Cosmet Sci 40:313-316

6. Maranzatto CF, Miot HA, Miot LD, Meneguin S (2016) Psychometrican analysis and dimensional structure of the Brazilian version of melasma quality of life scale (MELASQoL-BP). An Bras Dermatol 91:422-428

7. Handel AC, Lima PB, Tonolli VM, Miot LD, Miot HA (2014) Risk factors for facial melasma in women: a case-control study. Br J Dermatol 171:588-594

8. D'Elia MP, Brandao MC, de Andrade Ramos BR et al (2017) African ancestry is associated with facial melasma in women: a cross-sectional study. BMC Med Genet 18:17

9. Jarvik GP (1998) Complex segregation analyses: uses and limitations. Am J Hum Genet 63:942-946

10. Katz MH (2011) Multivariable analysis: a practical guide for clinicians and public health researchers. Cambridge University Press, Cambridge

11. Miot HA (2017) Assessing normality of data in clinical and experimental trials. J Vasc Bras 16:88-91

12. Norman GR, Streiner DL (2014) Biostatistics. The bare essentials, 4th edn. People's Medical Publishing House, Shelton

13. Chung BY, Noh TK, Yang SH et al (2014) Gene expression profiling in melasma in Korean women. Dermatology 229:333-342

14. Kim NH, Choi SH, Lee TR, Lee CH, Lee AY (2014) Cadherin 11, a miR-675 target, induces N-cadherin expression and epithelial-mesenchymal transition in melasma. J Investig Dermatol 134:2967-2976

15. Miot LD, Miot HA, Polettini J, Silva MG, Marques ME (2010) Morphologic changes and the expression of alpha-melanocyte stimulating hormone and melanocortin-1 receptor in melasma lesions: a comparative study. Am J Dermatopathol 32:676-682 
16. Passeron T, Picardo M (2018) Melasma, a photoaging disorder. Pigment Cell Melanoma Res 31:461-465

17. Tamega Ade A, Miot HA, Moco NP et al (2015) Gene and protein expression of oestrogen-beta and progesterone receptors in facial melasma and adjacent healthy skin in women. Int $\mathbf{J}$ Cosmet Sci 37:222-228

18. Brianezi G, Handel AC, Schmitt JV, Miot LD, Miot HA (2015) Changes in nuclear morphology and chromatin texture of basal keratinocytes in melasma. J Eur Acad Dermatol Venereol 29:809-812

19. Lee AY (2015) Recent progress in melasma pathogenesis. Pigment Cell Melanoma Res 28:648-660

20. Hexsel D, Lacerda DA, Cavalcante AS et al (2014) Epidemiology of melasma in Brazilian patients: a multicenter study. Int $\mathbf{J}$ Dermatol 53:440-444 